\title{
UNA ESCULTURA DEL SIGLO XVI EN MEXICO
}

\author{
POR \\ G O N Z A O O B R Gón \\ Conservador del Museo de las Vizcainas
}

En la parte sur de la ciudad, en la calle de Arcos de Belén, se alza la pequeña iglésia de Belén de Mercedarios. Hace un siglo marcaba el limite del crecimiento de México; hoy queda en el centro de la capital.

Es una interesante construcción del siglo xvir, erigida a expensas de doña Isabel Picazo, viuda del capitán Vázquez de Medina ${ }^{1}$ y renovada a mediados del siglo XVIII. Consta de una iglesia de planta cruciforme, con una sencilla portada barroca y su cúptula de bellas líneas. Se le anexó posteriormente una capilla perpendicular al eje del templo, a la que, en el primer tercio del siglo XIX se le dió la fachada que tiene sobre la calle de Arcos de Belén, de tipo neoclásico, bastante sobria.

1 D. Buenaventura de Medina Picazo, cuyo bello monumento sepulcral paede Perse en la capilla de Regina Coeli, era bijo de doüa Isabel Picazo. La gruesa fortuna de la familia Medina Picazo se emplé casi exclusivamente en el ornato de los templos capitalinos. 
En su interior pueden admirarse dos bellos retablos churriguerescos, uno particularmente rico, $y$ algunas pinturas interesantes.

No es mi ánimo extenderme sobre ellas, sino dar a conocer una imagen que en este templo se guarda, interesantísima por su historia, las tradiciones a ella ligadas y sus peculiaridades artísticas.

La descubri.en forma verdaderamente casual hace tres o cuatro años. Visitaba la iglesia acompañado por el sacerdote encargado de ella y me enseñó la Virgen de la Merced que, perdida entre las vestiduras que la cubrian, estaba en el altar mayor, asomando apenas la cabeza, una mano y parte del Niño. Cuál no seria mi sorpresa al encontrar, bajo la tela, una escultura toda en talla, estofada, con características muy primitivas. Al manifestar mi extrañeza y sugerir al padre que la expusiera sin los ropajes añadidos, me dijo que ya lo había intentado, pero que los fieles habían protestado diciendo que les habían cambiado la imagen. Me agregó que aquella era la célebre Virgen de la Merced, titular del Convento Grande de México.

Su historia, tal como la traen los cronistas coloniales, es la siguiente: "Y luego por marzo del siguiente año de 1595, (el Rdo. Padre Presentado Fray Francisco de Vera) se puso en camino para dicha Provincia, donde fué recibido de toda ella con la pronta obediencia que siempre ha acostumbrado tan docta $y$ religiosa Provincia. $Y$ ocupándose luego en la visita del convento grande de Guatemala, reconoció que en él había dos imágenes de nuestra Señora con la insignia y ropaje de nuestra religión, y como había dejado el convento de México sin tener en su iglesia y altar mayor una hechura de talla de Nuestra Señora; aunque tenía una de pincel de hermosisima hechura que hoy está en nuestra iglesia en un altar muy bien fabricado, de escultura dorada, y desde entonces se intitula Nuestra Señora de Buen Aire; tuvo por mejor, corno sin duda lo fué, el dicho Rdo. Padre Vicario general, que una de aquellas dos sagradas imágenes que tenía el convento de Guatemala, viniese por fundadora y patrona del nuevo convento de México; y aunque para ello tuvo grandísimas resistencias así de la ciudad como de los mismos religiosos, que ninguno quería que joya tan preciosa y tan de su estimación les faltase, fué necesario valerse de la maña para conseguir el intento.

$Y$ fué que hallando tan recia contradicción dejó pasar algunos días para sosegarlos, $y$ desvelarlos de su intento, y pasado casi todo el añn 
de 1595, puso con todo secreto la santa imagen en una petaca capaz, en que cupiese, con toda decencia y capacidad, y cerrada y liada la petaca con la soberana prenda que traia dentro, hizo que a media noche se la sacasen del convento en hombros de indios (que para este género de carguío se aplican ellos con gusto y facilidad) salió del convento sin companía alguna de religiosos, porque no se hiciese ruido y se supiese en la ciudad, pues es cierto que echándola menos saldrían los vecinos a quitarla, como de hecho, después de pocos dias se entendió el caso en Guatemala y salieron muchos a ver si la encontraban juzgando que iría por el camino muy encajonada y en mulas de carga, con gente española que la llevase, pero como todo se previno para el mejor acierto, aunque encontraban los indios con la carga no advittieron viendo sólo que hombres llevaban una petaca, que ni los mismos cargadores sabian lo que llevaban dentro de la petaca, y así aunque la encontraron, no dieron en la presa que buscaban.

"Volvieron los vecinos a la ciudad casi desesperados y tan sumamente enojados del caso, que estuvieron para apedrear al dicho Padre Vicario general porque los había defraudado de un tesoro de tanta estimación y enajenado su preciosa imagen, la cual fué caminando de pueblo en pueblo, con un rótulo que se le puso encima de la petaca que decia: "quien te encaminare a México, Dios le encamine;" y sin hacer más diligencias porque no se pudo hacer otra, nì se supo en Guatemala dónde estuvo la imagen, $y$ sin pagar a quien la trajese, ni hacer carta alguna en que se escribiese el caso, a los seis meses que salió de Guatemala, que fué por el año de 1596, se nos entró por las puertas del convento tan entera y bien tratada como si no hubiese caminado más de trescientas leguas; y fué cosa admirable que los indios que la entraron en el convento en sus hombros eran indios del pueblo de Cuitlahuac, que está en la laguna del contorno de México distante cuatro leguas de esta citudad, y preguntándoles que quien les había entregado aquella petaca, respondieron que el día antecedente la habían dejado en su pueblo otros indios, rogándoles que la trajesen a México, y entregándola se fueron a su pueblo sin dar más razón ni aun esperar la paga de su trabajo."

"De esta suerte se nos vino este inestimable tesoro a este convento donde fué muy bien recibida, no sólo de los religiosos, sino de toda la ciudad, pues luego al punto corrió la voz por toda ella, y no puedó persona de todas esferas que no llegase a darle la bienvenida, ofreciéndole varios dones de preseas de oro y plata para su adorno que hasta hoy se conservan, señal de alegría y reconocimiento con que se constituian to- 
dos por sus esclavos; como hicieron los reyes de Oriente con su precioso Hijo, cuando nació dichosamente en Belem. ${ }^{2}$

La iglesia de la que esta imagen era la titular, sólo nos es conocida por la litografia de la revista La Cruz. En ella se pueden apreciar su arquitectura, su artesonado, sus tribunas y sus altares. En el mayor se distingue la imagen en el nicho central y por cierto que está vestida. Además el Niño lo tiene en la derecha; probablemente se lo agregaron por la dificultad de vestir al que tiene la escultura.

Esta Virgen fué veneradisima y muy popular en su barrio. Hay que leer la descripción que en Chucho el Ninfo hace Cuéllar de las rumbosas procesiones, la función ostentosa (casi siempre costeada por los panaderos) en la fiesta de la Merced, en vísperas de la Reforma.

Llega ésta y uno de sus primeros actos es la destrucción de la iglesia grande y la casi total del convento. Aun con esto está relacionada la imagen de que hablamos, ya que según una tradición antigua, un fraile, tenido en opinión de santo, pronosticó que el convento e iglesia desaparecerían cuando la Virgen levantara la cabeza que tenía ligeramente inclinada $y$ esto se realizó en 1853.

Cierto o no, al ser derribada la iglesia la imagen fué transladada a la parroquia de San Pablo, donde quedó olvidada hasta que a principios de este siglo se restauró la Orden de la Merced y les fué devuelta la iglesia de Belén. Reclamaron la imagen; se les entregó y quedó colocada en el altar mayor.

En la actualidad ha terminado su azarosa historia en el altar lateral de la capilla, ya sin vestiduras, luciendo extraordinariamente a pesar de que es difícil apreciarla en la penumbra.

Describamos ahora la imagen. Tiene 1.26 metros de altlura y está tallada en un grueso tronco de cedro rojo. La Virgen está representada

2 Esta relación está tomada de la conocida Crónica de la Merced del padre Pareja, impresa en México en 1883. Algunos otros escritores coloniales la repiten sin modificación importante. Así la encontramos en el Zodiaco Mariano, del padre Florencia, en el Escudo de Armas de México, de Cabrera, e igualmente en la obra Crónica de la Merced, del padre Aldana. En esta última las dos únicas variantes interesantes que trae son la primera que dice que la imagen está estofada en oro y blanco, y la segunda, que caminó más de seiscientas leguas en vez de las trescientas que dice el padre Pareja. 
teniendo al Niño con la mano izquierda mientras la derecha, semicerrada, la extiende. El Niño levanta la diestra en actitud de bendecir, y con la otra mano despliega el manto de su Madre cobijando con él a dos cautivos, pues no hay que olvidar que la Orden de la Merced fué fundada para redimirlos; éstos extienden hacia él sus brazos en actitud suplicante. Están vestidos con una corta túnica, sin mangas y con grilletes en los pies. Del otro lado en la misma postura, dos frailes mercedarias, las manos juntas, levantan hacia la Virgen el rostro implorante.

E1 colorido de la escultura es extraordinatiamente bello y armónico. La túnica de la Virgen es en blanco marfil con un caprichoso dibujo en verde, rojo y morado. El manto, rojo y oro en la parte interior, al exterior es azul y oro. La túnica del Niño, morada, la de los cautivos roja oscura, y blanco marfil la de los frailes.

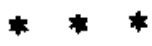

Al queter clasificar la imagen, o catalogarla dentro de un tipo conocido, empiezan las dudas y vacilaciones. La primera impresión que da es de una Virgen románica, sedente. Recuerda especialmente la Virgen de la Vega de Salamanca, romínica, o la existente en el Museo episcopal de Segovia, gótica; la primera del xII y la segunda de mediados del XIV. ${ }^{3}$ Por otro lado no tiene la rigidez y sequedad de las resculturas románicas. La cara de la Virgen es gótica, se la podría emparentar con algunas imágenes de fintles del siglo $x v$, por ejemplo, la existente en la catedral de Granada. Es el mismo perfil alargado, frenke amplia y ojos un tanto inexpresivos. - Además, ciertos detalles de la indumentaria son absolutamente góticos. Uno de ellos es el zapato redondo que deja asomar bajo la túnica, otra es el velo, que, prendido al pecho con el escudo de la Merced, le cubre la cabeza y del que se desprenden dos bandas que sujetan el pelo tras las orejas. Este mismo tocado, este velo igualmente dispuesto, lo encontramos en el retrato de Isabel la Católica atríbuído a Antonio del Rincón, y que existió en el Palacio Real de Madrid.

3 Historia del Arte Hispónico, por el marqués de Lozoya. Barcelona, 1931. T. 1. pág. 443 ,

4 En Spanische Plastik aus sieben jahrhunderten, por Georg. Weise. 1925. Iámina 93. El tipo de Virgen gótica sedente la trae Mayer en sa obra El Arte Gótico en España, láms. 41 y 42 y otros tipos de Virgenes románicas preden verce en Mayer: $E t$ Estilo Románico en España, láms. 66, 67, 69, 70, 71, 293, 205. 
Pero hay aparte otros factores, completamente renacentistas. Uno de ellos, el más importante, es el Niño. A pesar de que su actitud general, especialmente la diestra que bendice, se puede relacionar con Vírgenes góticas y aún románicas, la forma en que está concebiðo es absolutamente renacentista. Además, no está cubierto más qute por una camisita mal ajustada, cosa que no encontramos en la escultura anterior a 1520 . Tiene por cierto, un parecido con el Niño de la Virgen de Cuauhtinchan, escultura que ya es plenamente renacentista. Tanto los cautivos como los frailes se pueden catalogar también como escultura renacentista, un poco toscas, especialmente los segundos que son buenos por sus proporciones y la expresión de fervorosa súplica. Sus rostros son aun de serios conquistadores o de frailes enérgicos, reformadores a lo Cisneros.

Todos estos datos son tan contradictorios que es difícil llegar a una conclusión definitiva. Sin embargo, me atrevo a formar esta hipótesis. Esta escuitura fué hecha en América en la primera mitad del siglo xv1, entre 1525, época en que llegaron los mercedarios a Guatemala, y 1550 en que se estabilizaron en su convento, copiada de una escultura anterior que pudiera ser de marfil, con algunas variantes y modificaciones. Los datos que tengo para pensar así, son los siguientes: en primer lugar, la materia en que está hecha la imagen, que no se empleó en la escultura espafiola del siglo xvi y, en cambio, muy frecuentemente, en la americana. El original debió de haber sido una Virgen sedente. La copia no fué hecha así, y aunque a primera vista la Virgen da la impresión de estar sentada, en realidad está de pie, siendo desproporcionado el cuerpo en relación con la cabeza. El niño, cuya postura resulta, si su Madre está sentada, lógica y natural, en ésta está materialmente volando ya que la forma en que lo tiene sostenido la Virgen no es suficiente para detenierlo. La forma en que están cobijados frailes y cautivos, rarísima en escultura es, en cambio muy frecuente en pinturas y grabados de finales del siglo xIV en adelante.

Todo esto me hace pensar que la escultura peninsular que sirvió como modelo, pudo ser alguna Virgen gótica, sedente, que, al ser copiada por el desconocido escultor, la modificó y agregó los cuatro pequeños personajes de la parte inferior. 


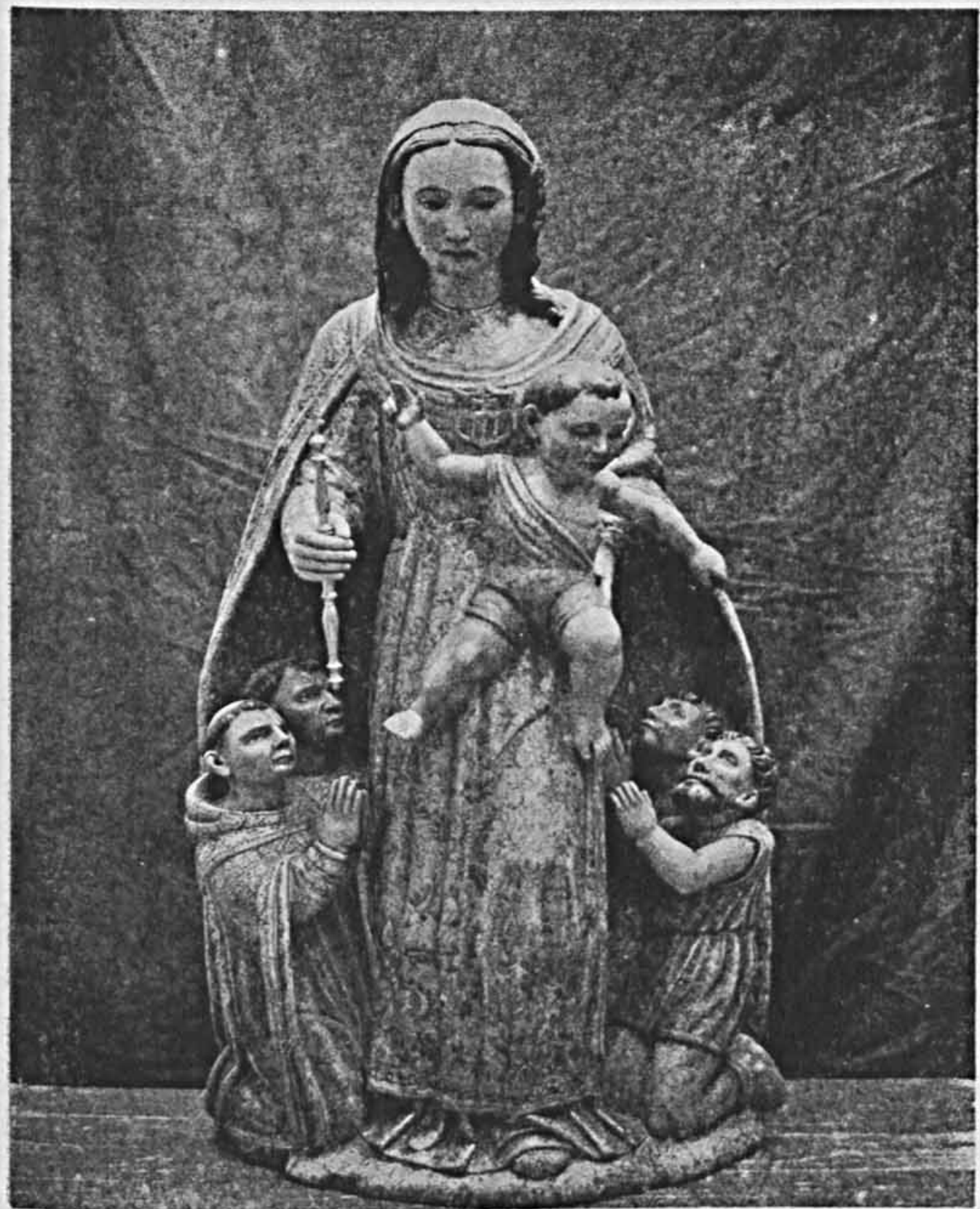

Fig. 1. Escultura de la Virgen de la Merced. Frente 


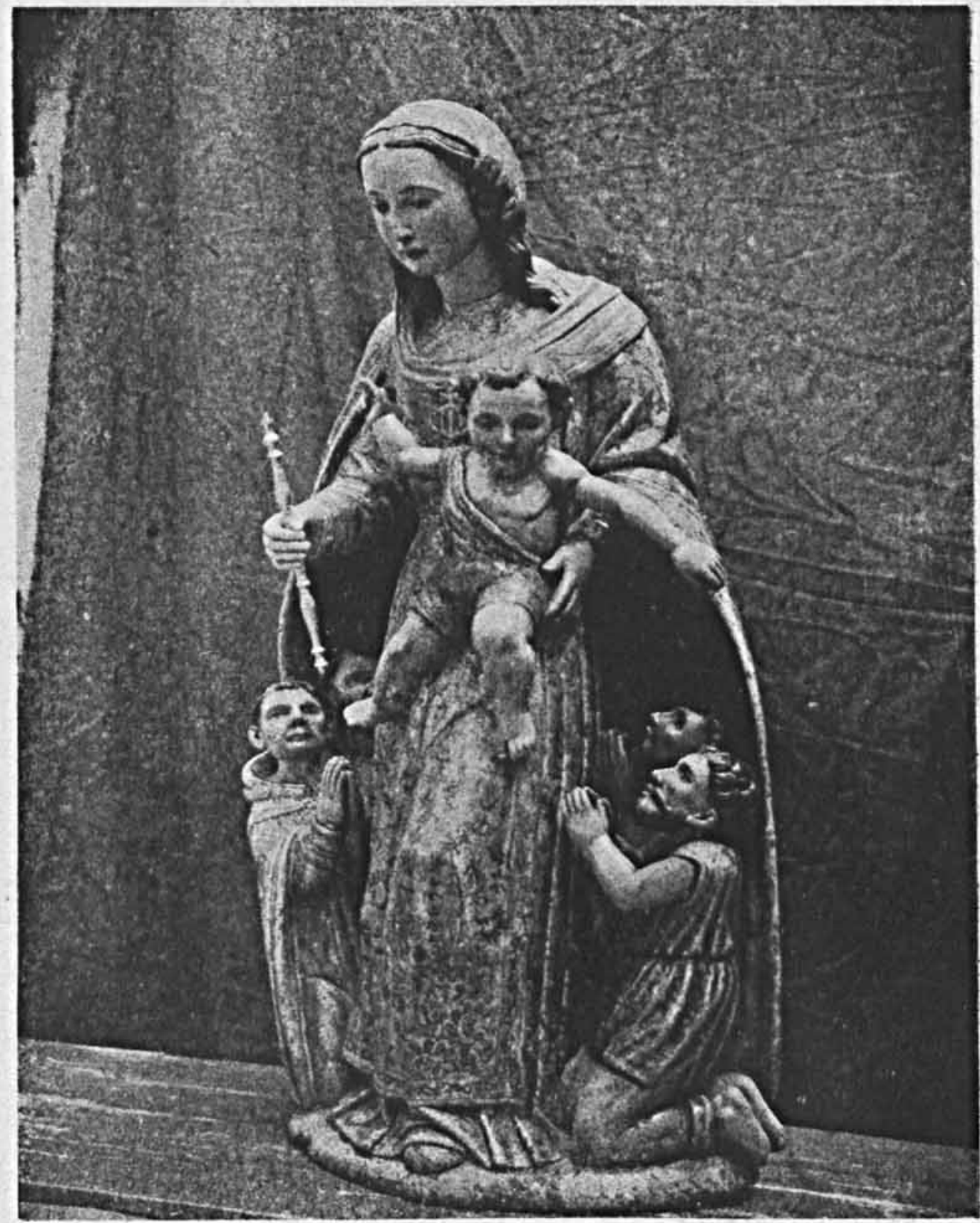

Fig. 2. La misma escultura en escorzo 


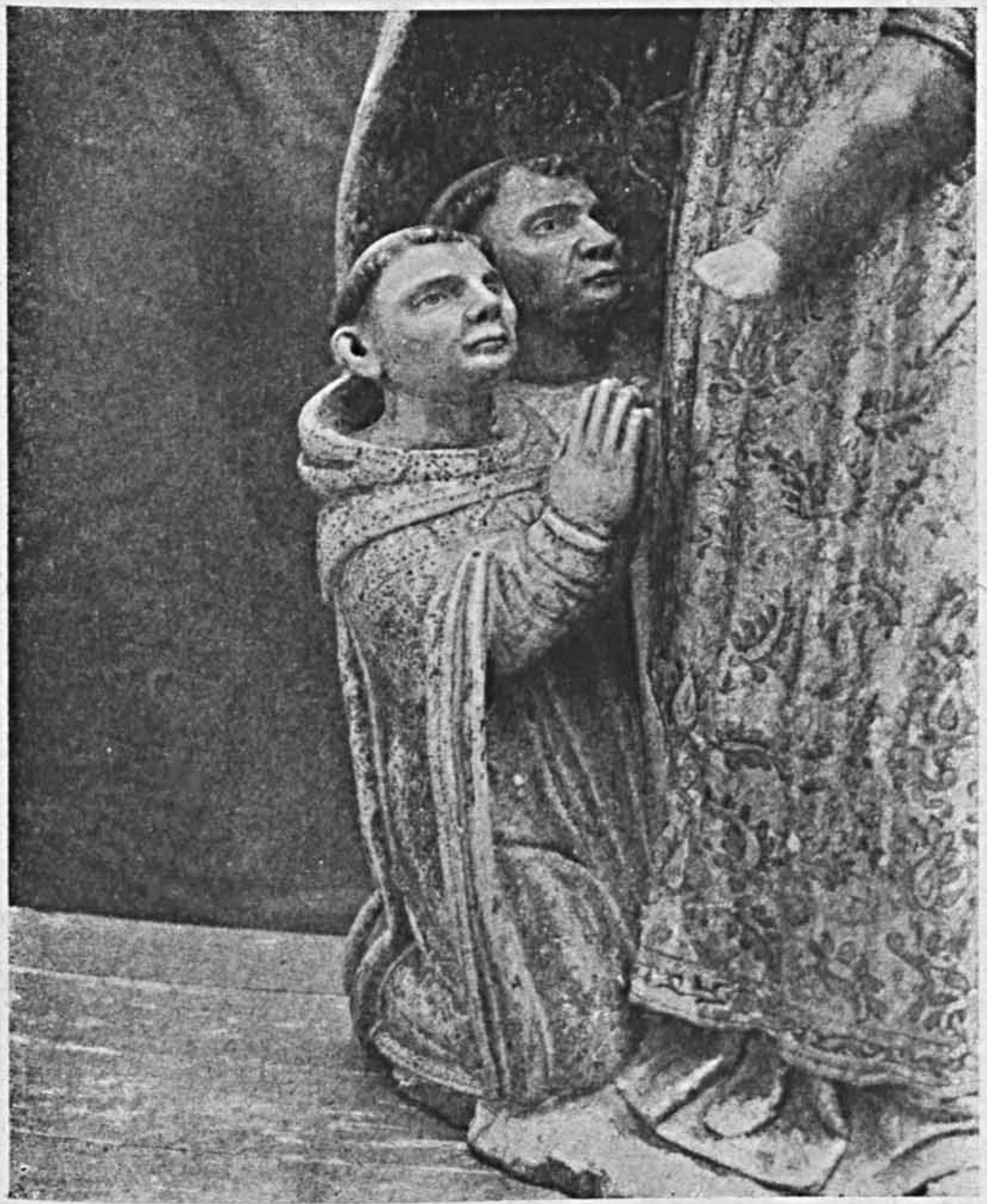

Fig. 3. Frailes mercedarios orantes. Detalle del anterior 

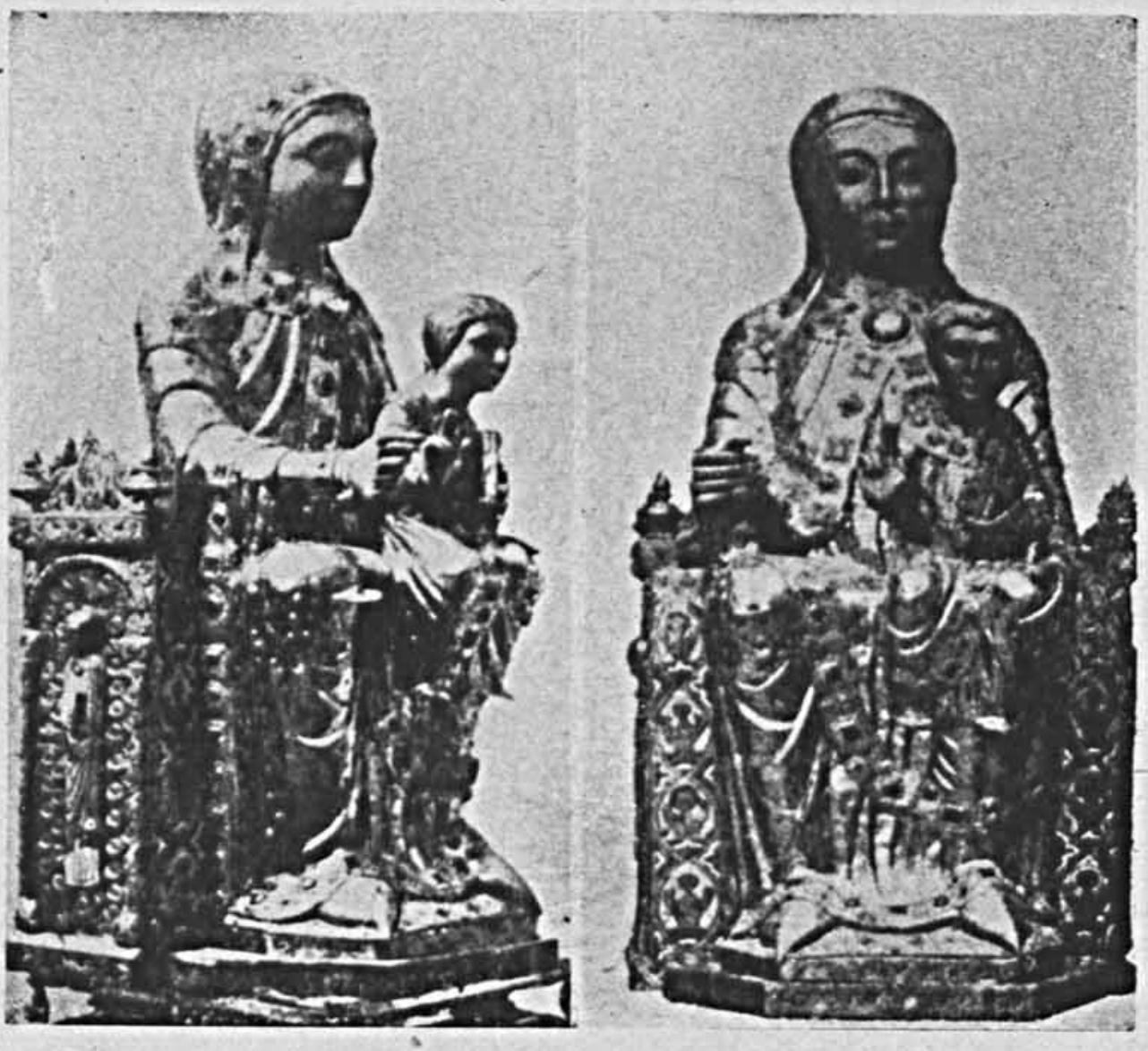

Fig. 4. Virgen de la Vega. Catedral de Salamanca, España. Principios del siglo XIV 


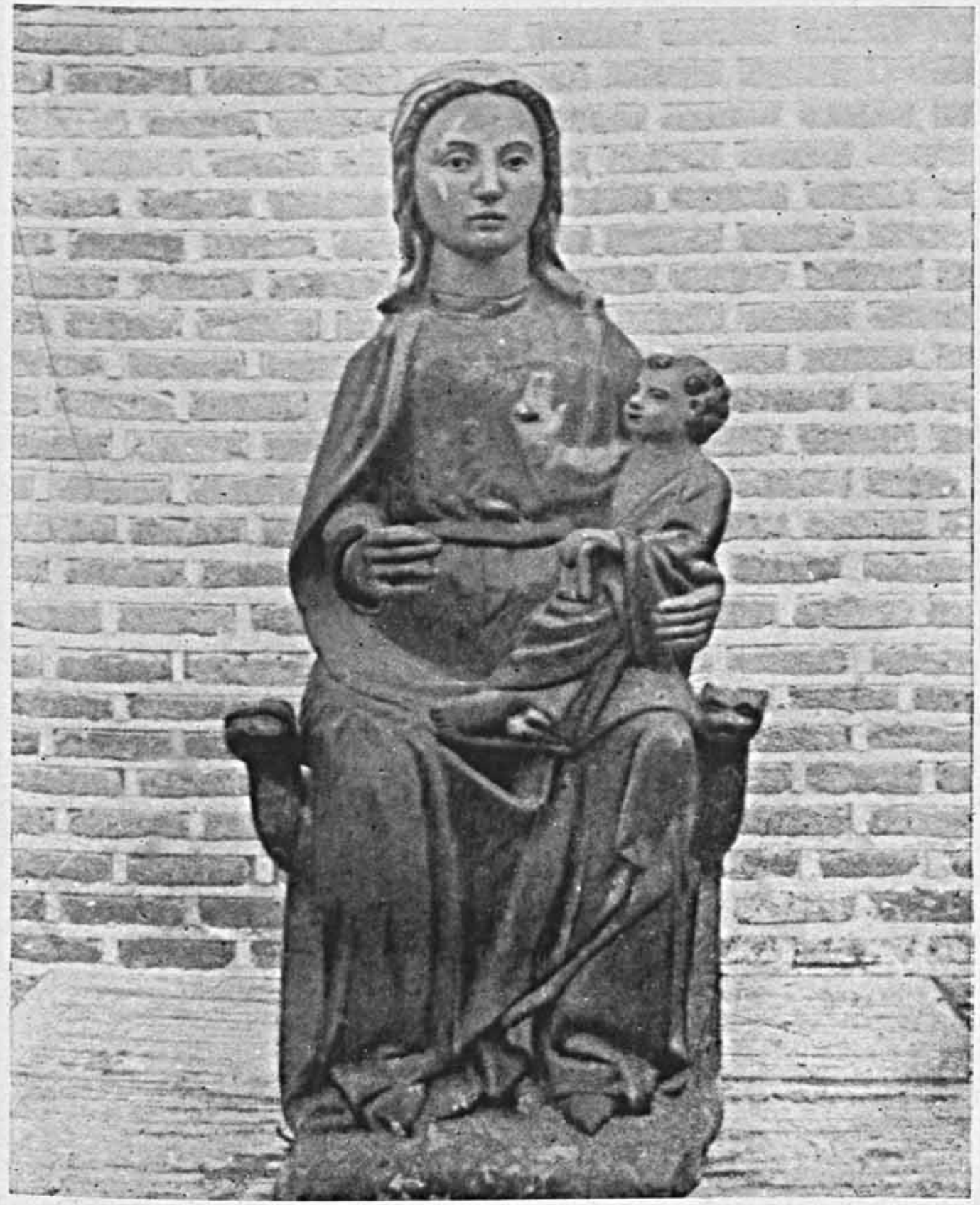

Fig. 5. Virgen del Museo Episcopal de Segovia. Mediados del siglo XIV 


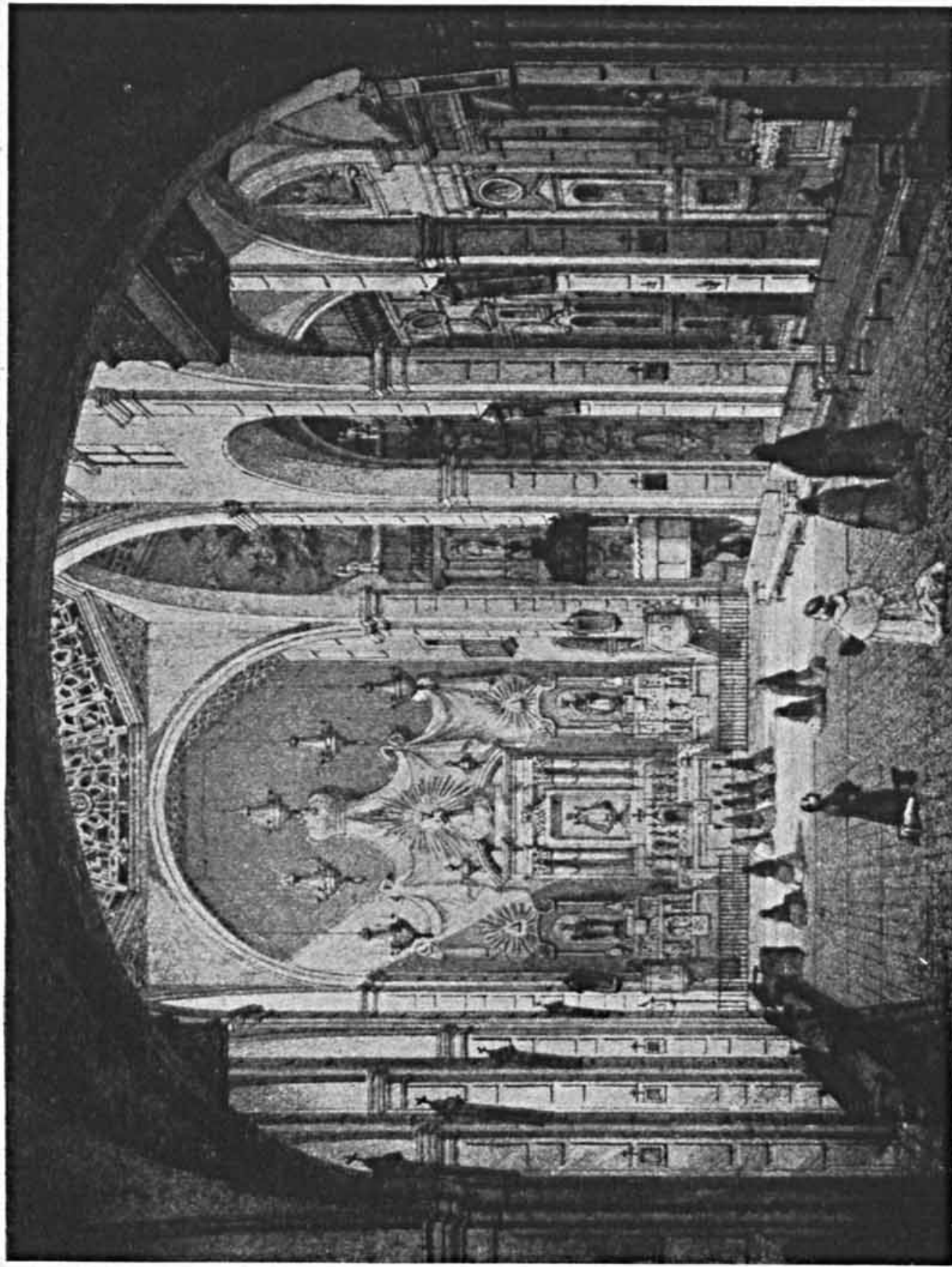

